\section{Re-Conceptualization of "Digital Divide" among Primary School Children in an Era of Saturated Access to Technology}

\author{
Ebrahim Talaee $^{a,{ }^{*}}$, Omid Noroozi ${ }^{\mathrm{b}}$
}

$\begin{array}{ll}\text { Received: } & 18 \text { May } 2019 \\ \text { Revised: } \quad 25 \text { July } 2019 \\ \text { Accepted: } \quad 01 \text { September } 2019 \\ \text { ISSN: } 1307-9298 \\ \text { Copyright } \odot \text { IEJEE } \\ \text { www.iejee.com }\end{array}$

DOI: 10.26822/iejee.2019155334

\begin{abstract}
This study conceptualizes "digital divide" among school children. The concept of digital divide is elaborated on the basis of the layers of technology adoption such as "access", "effective use" and "the social envelope" around children's use of home computers. In this study, a theoretical framework of "digital divide" is proposed consisting of social, economic, individual and cultural aspects of the digital divide among children. This theoretical framework suggests that socio-economic status effect goes beyond ownership and extends into meaningful education use of home computers. We argue that inequalities among children can strongly be affected by the economic/social/cultural environment around home computing i.e. parents' computing practices at home and the home learning environment. As a result, we argue that access to a supportive 'social envelope' is the area in which most digital inequalities exist rather than the physical access to the hardware or even usage time
\end{abstract}

Keywords: Digital Divide, Home Computer Use, Children, Primary School, Technology

\section{Introduction}

Statistics in many countries show near saturation of children's access to hardware. However, those who own hardware, use them in different ways (Facer et al., 2000). Some children consider home computers as natural and use them to support their creative production and learning while others view them as aliens and use them as little more than sophisticated games machines (Selwyn \& Facer, 2007). This 'structuration' of children's lives in terms of their interpretation of home computers should be discussed in relation to their wider social and cultural environments, particularly their family social class and cultural capital, gender, and parental digital involvement in the home. Our world is now surrounded by technology-enhanced learning environments and this has consequences for the way in which we educate our children as well (see Bose, 2017; Coffey, 2017; Ersoy \& Bozkurt, 2017; Huda et al., 2017).

This is an important issue due to a proven relationship between digital exclusion and social exclusion and the ways in which ownership and use of home computers/internet in the recent years are shown to increase children's life chances on one hand (Selwyn \& Facer, 2007) and widen the gap on the other hand (Livingstone \& Haddon, 2009). There has been a theoretical debate between cyber-optimists who see the internet as a great tool to bridge the traditionally social stratifications and cyber-pessimists who regard the new technology as a cause for greater inequality between the information rich and poor (Norris, 2001). Even among those who own computers and have access to the internet, evidence for a divide is emerging between social groups in their nature and quality of computer use (Morgan \& VanLengen, 2005). Therefore, the ways home computers are used by children actually reflect the meaning which is given to the home computers by a wider social and cultural forces rather than the machine or the child themselves. These include, but are not limited to, the family social class, parental involvement in Home Computer Use (HCU) and Home Learning Environment (HLE).
In other words, use of ICT is seen to underpin active involvement of an individual in the society i.e. 'social inclusion' - from playing an active part in one's neighbourhood and community to maintaining one's personal finances (Selwyn \& Facer 2007, p.9). Such social inclusion could unfold in different formats especially in online platforms ranging from daily exchanges of information to argumentation, counter-argumentation and reasoning in different social networking sites (see Coffey, 2017; Ginkel et al., 2019; Huda et al., 2017; Noroozi, 2017; Noroozi \& Hatami, 2018; Noroozi \& Mulder, 2017; Noroozi et al., 2011, 2012; 2013a, 2013b, 2013c, 2016, 2017, 2018, 2019a, 2019b; Valero Haro et al., 2018, 2019; Verstege et al., 2019). Stewart (2000) defines 'social inclusion' as a matter not only of access to new technologies and resources but also of 'participation in the determination of both individual and collective life chances' (Stewart, 2000, p.256). It encompasses full participation of individuals, families and communities in controlling their own destinies related to all aspects of life including education, employment, civic engagement and entertainment.

The concept of 'digital divide' was first used with regard to the technological disparity between developed and developing nations - the 'global divide'- but soon it was gravitated to the digital exclusion of individuals or groups of individuals within the countries - 'social divide' (Selwyn, 2003a, p.18; Wrest, 1996, p.85). 'Social divide' is used here to refer to the gap between information haves and have-nots within a nation. There is compelling evidence that children from poor families, working class households or rural communities are less likely to own a home computer or have other kinds of access to digital technologies in the UK (Selwyn, 2003b; Rice, 2002; Yu, 2006). Elsewhere, in the USA which is considered a North and privileged country in technology adoption, studies show a lower rate of internet penetration among the poor too (Ntia, 1999). In addition to the poverty as the dividing line of the social stratification, other factors such as race and ethnicity, educational level, age (access to new technologies inversely correlated to age), gender (with high proportions of males than females), family structure (e.g. dual parent 
families are more likely to be connected rather than single parents, one or two child households most likely to have access), physical ability (disabled people having less access) and neighbourhood (more economically prosperous regions are more likely to be connected) have also been shown to lead to this 'social divide' (Yu, 2006; Selwyn \& Facer, 2007).

The digital inequalities among different social groups in fact mainly demonstrate the traditional social stratifications in terms of Socio-Economic Status (SES), income and education. Governments around the globe have introduced large investments to address these access inequalities through free or subsidised computer and connectivity provisions to poor working class families. These investments are to prevent the re-production of the 'structuration' of the society because again cyber-pessimists 'emphasize deep-seated patterns of social stratification and the growth of an unskilled underclass' (Norris, 2001, p.125). Although this can be true, a chain of causality cannot be suggested on either sides: lack of access leads to less life chances and more likely to be socially marginalised later; those who are already disadvantaged will have fewer chances to access and use new technologies. Therefore, there seems to be an intertwined connection between technology and the society and any assumption of causality becomes problematic.

The academic literature also shows a debate on a persistent problem with the narrow conceptualisation of the notion of the digital divide. This conceptualisation entails a binary division between social groups - haves and havenots, information literates and illiterates, effective and none effective use. This view, as Warschauer (2004) notes, can fail to see the interaction effects of different factors in a child's development. Diverse groups bring different social resources to the table, for instance children from less educated parents who provide an acceptable level of HLE for their children are more likely to use home computers educationally than those who are from more educated families but thin HLE (Morgan \& Venlengen, 2005). Therefore, one advantage can cancel out a disadvantage and this view requires a holistic perspective to all social resources and relationships. The new technologies and home computers specifically, then, are woven, in a complex manner, into social systems and processes.

Interpretation of the digital divide in terms of 'social divide' still stresses the access side of the debate i.e. it tries to show the disparities in having access to the new technologies among groups of people in a nation. However meaningful access to ICT comprises more than providing computers and internet to the children and their families. There are some case studies in different countries which show the failure of ICT in education projects that did not consider other important factors such as physical, digital, human and social resources and relationships (e.g. Computer Lab project by USAID in Egypt, a 'Hole-in-the-Wall' project in New Delhi, see Warschaue 2003, p. 1-5). Therefore, it is important to revisit the digital divide concept and look beyond the access and connectivity rates and even frequency of computers/internet use in order to investigate the various meanings of ICTs for different groups in the society. The interesting question, then, is not the divide between 'connected' and 'not-connected' children or even between 'users' and 'non-users', although it is still relevant, the question revolves around the inequalities within the 'connected users'. This requires a different analytical framework which will be discussed in this paper.

In this manuscript, we first explain the need for re-thinking the digital divide. Then we elaborate on various contemporary frameworks for the digital divide which are already available in the literature. Next, we discuss various forms of capital and ICT use in the digital divide era from different perspectives including economical capital, cultural capital and social capital. Then we propose a new theoretical framework for new conceptualization of "digital divide" followed by discussions and conclusion.

\section{Re-thinking the Digital Divide}

Recently, the notion of 'digital divide' has attracted a revitalised attention trying to go beyond the access and connectivity inequalities. The new vision of digital divide questions the simplified understanding of the digital inequalities as a dichotomous deterministic notion of 'haves' and 'have-nots', 'connected' and 'not connected' and even 'users' and 'non-users'. The older approach, based on this assumption, even suggests digital divide indices and measurement tools and proposes simple ways to close and bridge these gaps in the society through providing universal access and connectivity (Jurich, 2000). However, as pointed out by a vast number of studies, this is not an accurate chain of assumption to think that ICT provision leads to its use and every kind of ICT use leads to a meaningful engagement which in turn results in a more comprehensive inclusion of all individuals in the society (Cuban, 2000; Hellawell, 2001).

Moreover, mere ICT access may generate another social stratification in regard to educational success. In support of this Attewell and Battle (1999) found that home computing may generate another 'Sesame Street effect' whereby an innovation that held great promise for poorer children to catch up educationally with more affluent children instead increases the educational gap between affluent and poor, between boys and girls and between ethnic minorities and whites, even among those with access to technology.

These problems led the researchers in the field to rethink conceptualisation of the digital divide and led them to provide a more theoretically-informed framework for the concept and to move beyond the popular and political conceptualisation. In this line researchers have reconsidered some of the concepts which were already taken for granted in the first generation of the digital divide. In the new generation which coincides with the first decade in the $21^{\text {st }}$ century, the terms 'digital technology' (or new technologies or ICT), 'access and connected-ness', 'use', 'the outcome of ICT use' and 'technological literacy' are revisited to consider them in a way that the multi-dimensional definition of the digital divide is taken into account.

What is currently meant by ICT is surely different to the conventional use of this term a decade ago. Conventionally ICT was used in a limited sense to refer to computers and internet. Based on this narrow view, the digital divide was understood as the inequalities between those who have access to computers and internet and those who do not. However, we now know that digital activities and interactions can take place via a vast range of technologies (such as mobile phones, games consoles, digital TV, PDAs, computer peripherals, Video telephones) and communication platforms (cables, wireless, microwave, WAP, open sourced networks). In terms of the content and services which are provided, one can also envisage an array of various digital content and services provided to the individuals and groups (such as web content, off-line content, application software, education and training services, voting, banking etc.). Individuals can do a vast amount of different activities using digital technologies which were not possible a decade ago. All these constitute the elements of the current techno-culture we are living in (Selwyn, 2003a). Any re-consideration of the digital divide concept should take this multi-modality and heterogeneous pattern into account. Therefore, it is wrong to assume ICT as an um- 
brella term for all these different technologies, contents, services and activities and narrow our definition to a limited number of hardware.

In regard to the concept of 'access', one can also argue that the conventional meaning of 'access' - making the hardware available to all individuals- needs to be re-visited. Not all accesses are similar and they do not necessarily lead to an 'effective' use as defined by the users not as perceived by the technology providers and politicians. For instance, the governments round the globe have invested hugely to equip the community centres with computers and internet connection in order to tackle the digital inequalities in some areas. One can definitely see that this type of access to ICT is crucially different to the access that some groups have on their personal computers in the home or at work. Issues of time, cost, quality of technology, privacy and safety are considerably different in these two types of access and these differences (or inequalities) will lead to different levels of quality use (Selwyn, 2003b; Selwyn, Marriott, \& Marriot, 2000). It is not just what children but where they study that is important to independent learning outcomes (Holloway \& Valentine, 2003). Even the location of PC in the home, whether it is in child's bedroom, living room or a common room for all family members, translate different quality of access. Therefore, the context of access plays a part in the level and quality of ICT use. The relationship between access to ICT and use of ICT is very complex and the former does not necessarily lead to the latter. If it leads, the use of technology does not entail 'meaningful' use or what could be termed as 'engagement'. Selwyn (2003a) defined engagement as where one 'exerts a degree of control and choice over the technology and its content thus leading to meaningful, significance and utility for the individual' (Selwyn, 2003a, p.23).

So this discussion leads us to the impacts, effects and consequences of ICT use and its significance in the digital divide debate. One should question the differences (or disparities) in the impacts that a given digital technology can have for similar groups. If playing a more active role in the society and engaging in one's and community's destinies is targeted for the ICT use, then, as some studies have shown, the 'social participation' framework/index should replace the current 'user' vs. 'non-user' dichotomous framework in the digital divide debate (Hadden, 2000; Warschauer, 2004; Corea, 2000). This aspect of the digital divide deals with the inequalities in the outcomes of ICT use. This is especially important because the technology is often likened to a knife which can be used for good and for bad. For similar peers, one can argue that the internet and home computers can have very positive outcomes (education, play, team working, socialising etc.) for one individual and negative outcomes (anti-social behaviour, depression, physical problems, less school work etc.) for another.

The appropriate outcome can be benchmarked against the 'relevance' of ICT use within a broader social, cultural, personal and psychological context of one's daily life. A good example is the current concern in low level use of ICT in classrooms by some school teachers in spite of having effective access to suitable technologies in schools and at homes (Scrimshaw, 2004; Cunningham, Kerr, McEune, Smith, \& Harris, 2003). ICT use is still felt to be irrelevant to their daily lesson planning and delivery. The wider context includes factors like age, gender, time, motivation, peer pressure, ICT skills, availability of appropriate content and ease of use, past experiences of using ICT in the class, technical support, test pressures etc. which should all be considered when investigating the disparities between teachers.

Still another concept which needs to be revisited in order to provide a deeper understanding of the digital divide is 'technological literacy'. Since 1980s there have been debates about the need for individuals to acquire 'technological literacy' over and beyond the traditional 3Rs literacies. Therefore, national and international initiatives started to teach the basic technology skills to individuals (such as teachers, parents, employees, pupils etc.). The very common certificate obtained by many was (and is) the European/International Computer Driving License (ICDL) which shows the mastery of using computers/internet and general Office application. However, there is research evidence showing that although it is necessary to operate on computer, it is not enough (Postman, 2011; Oppenheimer, 1997). In fact, one can see the inequalities in meaningful and engaged use of technologies even among those who have these basic skills. The effective use, within the skills and competencies debate, is shown to be reliant on 'a set of creative and critical skills and understanding required to productively engage with technology use' (Selwyn \& Facer, 2007, p.15). These new multi-literacies include, but not limited to, a wider 'technological literacy' (e.g. Web.2 technology), 'information literacy' (e.g. analysis and evaluation of information sources through broader critical skills rather than computer skills), multimedia literacy (ability to use and produce a combination of texts, photos, graphics, audio and video in a single product), technology-mediated communication literacy (how to establish and manage online communications for the benefits of oneself and groups such as weblogs, discussion groups and training) and functional literacy (the ability to apply these skills in education, work and daily life). Such literacies are distributed unequally in the society even among those who have access and use a variety of new technologies and the digital divide debate should take this aspect into account too.

In summary re-consideration of the notion of 'digital divide' through re-visiting some of the related concepts implies the importance of the wider social and cultural context surrounding ICT activities and practices. As Buckingham (2004) concludes understanding the childhood within the current rich techno-culture requires situating 'their use of new media in the context of wider-ranging social, economic and cultural forces' (Buckingham, 2004, p.125). Therefore, now the question is how to frame these various factors which lead to the use of digital technologies by an individual or a group of individuals but not by another. The following section discusses different frameworks.

\section{Contemporary Frameworks for the Digital Divide}

As explained above, ICT use is a social action and it is shaped mainly by social contexts (although some personal self-interested factors also play a part). Taken this into account, a number of authors have begun to map out the notion of 'digital divide' which demonstrate the hierarchy and the complexity of the concept. For instance, DiMaggio and Hargittai (2001) moved away from the digital divide concept and proposed 'digital inequalities' among people with physical access to ICT. They named five main factors in playing a part in digital inequalities: technical means (connectivity modes and speed), autonomy (e.g. using ICT from home or public places, supervised or un-supervised), skill, social support and purpose (e.g. whether using for increase of productivity or entertainment). Similarly, Warschauer (2004) saw the digital divide in terms of disparities in having access to four types of resources in order to use ICT effectively to access, adapt and create knowledge.

Physical resources refer to access to hardware and connectivity. Digital resources encompass the online material. Human resources refer to the required literacy and skills and social resources concern the societal structures and community that support ICT use. The arrows from the resources show that each resource is contributing to ef- 
fective ICT use and the arrows towards the resources ascertain that each resource can be an outcome of effective ICT use too. He considers 'social inclusion' as the suitable framework for the digital divide notion and concludes that 'if handled well, these resources can thus serve as a virtual circle that promotes social development and inclusion. If handled poorly, these elements can serve as vicious cycle of underdevelopment and exclusion' (Warschauer, 2004, p.48).

In the same line, Selwyn \& Facer (2007) criticised the traditional conceptualisation of the digital divide and argued that there is a 'pressing imperative to develop a wide-ranging agenda which sets out to address the multiple layers of the digital divide' (Selwyn \& Facer, 2007, p.23). They then proposed a charter for change, which goes beyond the digital divide, and suggested four entitlements for every individual in the digital age:

1. "All individuals are able to exercise an empowered and informed choice about their use or nonuse of ICT.

2. All individuals have ready access to the requisite social and technical support, skills and know-how to support their use of ICT.

3. All individuals have ready access to ICT-based content and services which are relevant and useful to their needs and interests.

4. All individuals have ready access to a full range of ICT hardware and software." (Selwyn \& Facer, 2007, p.28).

The entitlements clearly show that access to hardware is still important but comes as the last priority because there appears to be an increasing gap in the quality of use among those who have access to ICT. This framework is very similar to the four types of resources that Warschauer (2004) included in his model and discussed above. However, Selwyn \& Facer (2007) also recognise that an integral aspect of ICT use or non-use is that 'of individual agency and choice'. They differentiate between ICT use and a 'smart' use i.e. using ICT 'as and when appropriate'. In this sense 'not making use of ICT can be a positive outcome for some people in some situations, providing that the individual is exercising an empowered digital choice not to do so' (Selwyn \& Facer 2007, p.14).

Still another repeatedly cited analytical framework for the notion of the digital divide is the four-layered model of access definition (Van Dijk, 1999, Van Dijk \& Hacker 2003). They proposed a multi-faceted concept for access in which the following four kinds of access should be taken into account if the information inequalities are supposed to be defined beyond possession of technologies:

1. Mental access: mental, subjective and emotional drivers and barriers of access: these entail experiences of failure in technology use leading to insecurity of being excluded and of developing negative attitude to technology. All lead to 'computer anxiety'. Age, gender, low levels of education and functional illiteracy are shown to be strong predictors of this type of divide among individuals and groups.

2. Material access: ownership of computers and network connections.

3. Skills access: All instrumental, informational and strategic skills: the first refers to the operation skills of the machines and software, the second defines searching skills for information using the digital tools, the last refers to skills of using and applying information for one's own purposes and to improve one's position to participate more widely in the community. It is interesting to see that individuals' education level, as shown in the Netherlands' data used by Van Dijk and Hacker (2003) was not as a strong predictor as age and gender for the inequalities in instrumental and informational skills.

4. Usage access: different uses of the digital technologies from games playing and online watching to social networking, obtaining a university degree, working at home and designing. Again gender, age, education and to a lesser degree income showed significant associations with levels of particular uses of ICTs (Van Dijk, 2006).

Van Dijk's analytical framework for the digital inequalities is a more comprehensive one, although it has not been used widely in large-scale studies to provide empirical data for it and to be able to generalise the findings. This is partly because the 'skills and usage accesses are not easy to operationalise and more importantly these four layers of inequalities themselves have a multi-faceted nature. Having reviewed different contemporary frameworks which all go beyond the binary perspective for the digital divide, I argue for a model to explain the notion of the 'digital divide' based on both personal and structural factors which influence children's engagement with home computers (see also Talaee, 2019; Talaee et al., 2019). Personal factors refer to child's individual characteristics (e.g. gender) and structural characteristics refer to the surrounding social, cultural and economic resources available to the child through family, peers, community and school. Through drawing upon Bourdieu's concept of different forms of capital (Bourdieu 1990, 1997) and analysing its application into child's technology use (Selwyn, 2003a), an analytic framework is proposed here to understand the various mediating factors which lead to use (or non-use) of ICT and different types of computing activities among individuals or groups of individuals. The following section gives an account of three forms of capital followed by the introduction of the proposed analytic framework.

\section{Forms of Capital and ICT Use}

Bourdieu (1997) argued that understanding of the inequalities among social groups in the community should not be limited to the economic sphere but it requires investigating a vast array of different fields such as leisure, work, parenting etc. One area which now proves to be an important field is the use of the new technologies field, because of the integral part it can play in individual's participation in the community. Bourdieu proposed that in each of these fields, including ICT use, an individual can benefit from three forms resources - or capital- in order to compete with others. However, as different individuals or groups of individuals have access to varying levels of these resources, the gaps among the groups will arise.

There have been studies in the ICT in education literature which have applied this framework to explain differential patterns of technology use (or non-use) in the society (Selwyn, 2003a). The framework was used to illustrate the ways in which social class come to structure children's use of home computers. The model is also adopted for this study because children's various use of home computers is shown to be highly socially-rooted within a context in which individual and family's possession of economic, cultural and social capitals play an important part (Facer et al. 2000; Selwyn, Gorard, \& Furlong, 2006). ICT use as shown above is not merely having access to new technologies or even observing individuals using it. It is both a social action and a personal self-interested one i.e. both individual 
characteristics (e.g. gender, age) and social characteristics (parental level of education and parental practices at home) play a part in determining technology use and the nature of this use. The model of different capitals can entail both individual and social level aspects and analyses the impact of different forms of capital on individuals' use of technology. In saying this, it should not imply that only the factors underlying these three forms of capital determine individuals' level and nature of ICT use. However, they form a great majority of factors which structure the choices that individuals face in using or not using ICT.

\section{Economic capital}

Economic resources underlined much of the digital inequalities in the latter decades of the $20^{\text {th }}$ century and up to the present time. Cost of the access to digital technologies proved to be an important factor and it still hinders a considerable number of families to have access to the hardware (Valentine et al., 2005; Dutton \& Helsper 2007). The research shows that both the one-off cost to purchase the hardware and more importantly the maintenance and upgrading of the systems and connectivity put off some families, especially those who are at the lower end of the multiple socio-economic disadvantage, to have access to ICT. The economic capital in relation to the ICT use does not entail only the cost of the hardware and its maintenance but it includes providing sufficient requirement to move to higher stages of ICT use. Selwyn (2003a) named these stages as 'theoretical/formal access', 'effective access', 'use', 'engagement', 'short term outcomes' and 'medium/ long term consequences'. Some of these extra requirements which require economic capital are the ample time, comfortable space and required software and computer application. There have been cases where the hardware -usually a connected computer - has provided but the individual did not go through the next stages of ICT use.

Therefore, even among those who have the financial resources to provide the access to the hardware and internet, one can differentiate the ways in which various levels of economic capital can differently structure the individuals' computing world. This can be both in the form of providing more advanced technologies and tools such as colour printer, wireless access, special software etc and in the form of the family values about consumption and the value of saving. The former was shown to play a central role in the quality of use and moving up the stage ladder of ICT use (Murdock et al., 1996). The latter was shown in case studies of children using home computers by Facer et al. (2000) in which the use of home computers by one of the children, for instance, reflected family values about the importance of 'do-it-yourself' in getting the best value for money rather than paying for all goods and services. As shown in this discussion, then, the nature of computer use is firmly grounded in the material and economic resources of the household, although the theoretical/formal access limitations to ICT might be claimed to be vastly overcome. In addition to the economic capital, other forms of capital available to the individuals also play an integral part in structuring the life opportunities in using ICT.

\section{Cultural capital}

Cultural capital, for Bourdieu, denotes the cultural resources that one accumulates throughout their life. Some individuals inherit cultural capital in the process of 'habitus' formation since birth from the family, school, work, social networks etc. In relation to the educational system and levels of parental involvement, for instance, Lee and Bowen (2006) have enumerated three forms of cultural capital: personal attitudes, knowledge and dispositions gained from experience, connection to education-related objects (e.g. books, computers) and connections to edu- cation-related institutions (e.g. schools, libraries). Therefore, cultural capital can be embodied, objectified and institutionalised. In regard to ICT, the embodied form of cultural capital can be through acquiring ICT knowledge and competencies in the form of informal/formal learning. The objectified form can be exposure to ICT books and magazines, setting up weblogs and membership in online communities. Institutionalised form of cultural capital can be realised through obtaining formal ICT certificates. One can clearly see that the process of habitus formation- i.e. socialisation into the techno-culture - did not happen for a great majority of parents - especially older ones - because the new digital technologies did not exist so widely even two decades ago. Therefore, these parents have accumulated a small amount or even no cultural capital in terms of personal dispositions and attitudes. This, in turn, leads to reduction of the ability of parents to obtain social capital as well because as Lareau (2001) notes 'when the habitus of the individual meshes with the habitus of the broader culture [i.e. field in Bourdieu's terminology], it is often invisible' (Lareau, 2001, p.65). In contrast, when they differ, parents can feel less able to tap the potential of friends, colleague's and all those people in their social networks and resources. In line with this, some authors distinguish between the culture of $21^{\text {st }}$ century generation of children and call them 'digital natives' with having a 'digital culture' and that of the older generation and call them 'digital immigrants' with having an 'analogue culture' (Palfrey \& Gasser, 2011). The differences in possession of various forms and levels of cultural capital can lead to different 'readings' of cultural activities and tools based on particular 'categories of perception' that an individual develops (Bourdieu,1986). Computers, as one of the dominant forms of cultural tools of the current age, similarly come to mean differently to people with different cultural capital.

This different interpretation of home computer use was shown in Facer et al.'s (2000) case studies in which children's 'reading' of home computer use - a cultural activity - patterned against what their family brought to the table in terms of their cultural capital. They showed that some children had a 'surface reading' in which they considered home computers and technology 'as a fascinating end in itself' while another child, with her parents having different cultural capital, 'read' computers as a useful support for the development of traditional forms of literacy expertise. Bourdieu himself recognised cultural capital as an important element of machine use and explained that: 'to possess the machine, he/she only needs economic capital; to appropriate them and use them in accordance with their specific purpose he must have access to embodied cultural capital; either in person or in proxy' (Bourdieu 1997, p.50).

Cultural capital plays an integral part in moving up the stages of ICT use into effective and meaningful application of the new technologies in which the desirable learning outcomes are more likely to happen. These outcomes are often mentioned as the grand claims of ICT affordances in the academic literature such as 'thinking skills', 'higher order skills', 'creativity and spontaneity'. However, they cannot be achieved unless all economic, social and cultural resources are provided to support an individual's ICT use. Some authors have named these factors as 'technological capital' as both an addition and subset of Bourdieu's forms of capital in the information age (Selwyn, 2003a; Hesketh \& Selwyn, 1999).

\section{Social capital}

Social capital is defined by Bourdieu himself as 'the aggregate of the actual or potential resources which are linked to possession of durable network of institutionalised re- 
lationships' (Bourdieu, 1997, p.51). Social capital contains three components: the obligations and expectations of reciprocity in social relationships, norms and social control, and information channels (Coleman, 1988). Social capital is viewed as a means to an end, a socially desirable end, for example a means by which an individual can draw upon sources of advice to help use powerful computer systems that a vast majority of users may not fully use. In regard to ICT use, social capital obtained through networks at work place, hobbies, friends and family members, organisations and institutions and other social and educational experiences can take the form of information (e.g. recent educational or service website/software, online safety issues), skills (e.g. how to use an application software) and access to resources (e.g. books, exchange of computer programmes).

There is compelling evidence that social capital has been recognised as an integral element of, and a source of inequality for, individuals' ability to effectively engage with the new technologies (DiMaggio \& Hargittai, 2001). Moreover, people from different social class and demographic background have access to different forms of social capital which in turns leads to various forms of computer culture in the home, community and the nation (Yu, 2006). Each group brings different types and levels of social capital with themselves because they have made various social connections. Moreover, the children themselves make social networks to support their technology use through schools, online communities, local centres, mosques, churches etc. (Facer et al., 2000).

Children's pattern of home computer use is therefore influenced greatly by both the parents and the child's possession of social capital. However, as Bourdieu argued one important source of inequality in access to relationships is the lack of fit between an individual's culture and the culture of the larger society. He used the terms 'habitus' and 'field' to explain this. 'Habitus' is a system of 'disposition to act, think and grasp experience in a certain way and it results from social training and past experience' (Lareau, 2001, p.256). A 'field' is 'a structured system of social relations at a micro and macro level' (Grenfell \& James, 1998, p.56). When one's 'habitus' fits with the 'field' they manage to make larger social networks. In terms of children's home computer use, some parents enjoy an advantage in accumulating a bigger social capital and offering a richer context for their children's effective home computer use. These parents are usually those who are young, have recently been in education and training or their work requires them to use computers (Somekh, Mavers, \& Lewin, 2003). In this way their system of disposition to act 'digitally' is consistent with the requisite of the information and communication age which children are exposed to on a daily basis. Obviously there is a close interrelationship between economic and social capital factors in determining the opportunities for children to use home computers. These two forms of capital are also interwoven into the levels and types of cultural capital that an individual can also accumulate. Many digital inequalities in new generation can be related to the differentiation in the type and levels of economic, social and cultural capital that individuals or groups possess.

\section{Proposed Theoretical Framework for New Conceptualization} of "Digital Divide"

Figure 1 shows the proposed analytic framework. It is partly adopted from Livingstone and Haddon's framework to analyses children's online activities by children in EU but their framework is designed to analyses at two levels of country and individual. Moreover, they have not included the concept of capitals in the framework (Livingstone \& Haddon, 2009). It centres on children's extent of home computer use and their computing activities in the home. The integral question within the digital divide debate now, is the inequalities among children in taking up the technology opportunities and overcoming the potential risks. Therefore, opportunities and risks are focused in the centre of the framework. The most common digital opportunities for young children are those which support their educational success in school. A fair body of research studies have investigated the association between HCU and children's educational achievement. At the same time there are some inevitable risks when children go online and different children can have different reactions to the risks depending on all those individual characteristics and surrounding and resources. However, the risks are only included in the framework to make it more comprehensive and there are no data on online risks to be analysed in this doctoral thesis. On the other hand, within different computing activities that children do some are generally considered as more relevant to children's school achievement (e.g. use of spelling software) than others (e.g. games playing). All these various home computing activities were shown to be influenced by an array of factors which are classified in Figure 1. In order to reach to the core stage i.e. taking up the computing opportunities, children have to go through prior stages. These are shown by four boxes around the core oval as having access to home computers/internet, developing all three types of digital skills, adopting a positive mental attitude towards new technologies and being able to use home computers effectively (e.g. sufficient time, privacy). Both the core objective and the four prior stages of home computer use are influenced by the child's individual characteristics (e.g. age, gender, disability) and the economic, social and cultural resources that children possess.

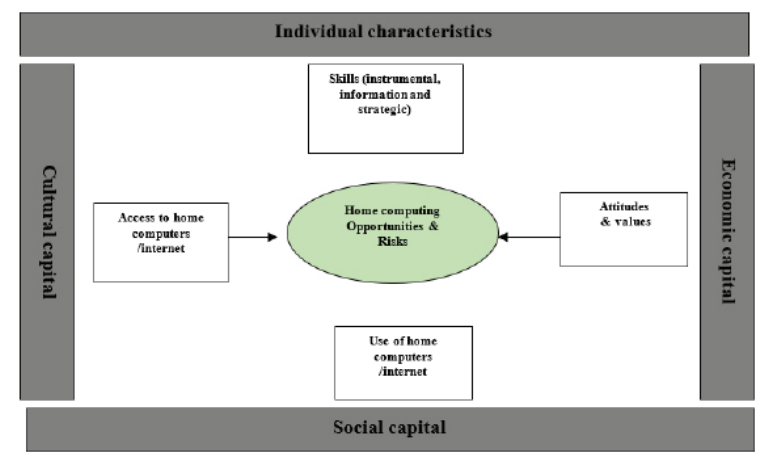

Figure 1. Proposed Analytic framework for reconceptualization of "digital divide"

In order to operationalise economic, social and cultural capital, the literature depicts a variety of methods and indices. Economic capital was shown to be the most common and less difficult concept to measure and parental income has been generally considered as its indicator (Valentine et al., 2005). The problem with this could be the fact that although the data might show that a group of children whose parents lie within an income range have access to home computers, the age and the technical capacity of the hardware -which could be very varying- they have access to are not clear. Most large scale quantitative studies of home computers have taken economic capital into account to explain the technological disparities (e.g. Dutton \& Helsper, 2007; Harrison et al., 2002). However, operationalisation of social and cultural capital has proved to be difficult - or limited - in most ICT studies, especially those carried on large samples. Therefore, proxies like parental educational level, occupation, social class, levels of cultural activities inside and outside the home etc have been considered to grasp part of the social and cultural capital available to the families (Valentine et al. 2005; O'Dwyer et 
al., 2005, 2008). A clearer picture of the social and cultural capital and their impacts on giving different meanings to and levels of use of the computers is provided by smaller scale case studies (e.g. Plowman, McPake, \& Stephen 2008, Davies et al., 2008).

In addition to the financial resources required for the families to provide access to the hardware, there is an important need to make a supportive, encouraging and stimulating environment in the home for children to move up the stages of ICT from theoretical access to meaningful engagement and desirable outcomes. This is because recent studies show that although the divide in access to computers and internet among school children is narrowing, a gap in the quality of use and skills required to maximise the benefits of technology use is appearing and widening (Selwyn, 2004; Lazarus \& Mora, 2000). Quality of use mainly refers to types of use (e.g. for school work, playing games, social networking etc.), attitudes towards internet use and overall internet literacy. These disparities deal with social differences in the ways computers are used at home and school. Not all uses of home computers have educational benefits and there is a need to a 'social envelope' around computing - the attitudes, competencies and involvement of parents and older siblings- in order to maximise the benefit of ICT-based activities (Attewell, 2001). The literature shows that parental encouragement, attitude, support and engagement in using home computers/internet for educational purposes, particularly for primary school children, seem to play an important role in exploiting new technology for academic purposes (Somekh, Mavers, \& Lewin, 2003; Valentine et al., 2005). Parental encouragement itself is reported to be a function of their education, ICT skills, occupational standing and nature of their jobs (Morgan \& Vanlengen, 2005).

\section{Discussion and Conclusion}

In order to discuss the findings of the present study within the analytical framework put forward for the notion of the 'digital divide'. It is important to recall the assumption made for this study about effective home computer use: it was assumed that use of home computers for educational purposes is regarded as effective use or taking up ICT opportunities while using home computers for recreation was regarded as non-effective or a risk. It was argued before that the new conceptualisation of the digital divide addresses the digital inequalities among individuals and groups of individuals in terms of the level at which one can take up digital opportunities and overcome potential risks.

The framework suggests that the final and core layer at which the digital inequalities should be discussed is the extent to which individuals take up the home computer opportunities and overcome its risks. However, before that there are other pre-requisites which should exist for an individual in order to reach to the core level. These pre-requisites are physical access to home computers/internet; having the opportunity, time, suitable home space and other factors to realistically use home computers; having the required skills to use home computers; and finally acquiring a positive attitude towards technology use. The proposed framework also suggests that an individual's effective and meaningful use of home computer (i.e. taking up HCU opportunities for educational success) and provision of all those four pre-requisites are a function of three main capitals and children's own personal characteristics. These are in fact the 'social envelope' required around effective home computer use as - in the strict sense - not every HCU can be considered as effective (Van Dijk, 1999).

The proposed analytic framework also shows that 'attitudes and values' toward computers are as important as skills, access and use. Parental engagement in the home to use home computers with their children in school-related activities might show their positive attitudes towards the affordances of technology for education. Moreover, the data in the present study showed that over and beyond parenting practices in the home in relation to home computers and HLE, the family socio-economic status (SES) is still a significant predictor of taking up the ICT opportunities. It is argued that the family's values and attitudes towards ICT are, at least partly, captured by the social status of the family because of the professional networks for parents with higher job status.

Finally, it is important to recall that the outcome measure is educational use of home computers, not merely home computer ownership. Previous studies that have reported the digital divide in terms of home computer ownership have been influenced much by the family SES (e.g. Hayward et al., 2002). However, our framework suggests that SES effect goes beyond ownership and extends into meaningful education use of home computers. Family SES can be in fact a proxy for activities, values and attitudes that parents do, share and promote in their family and social networks which exist between families and friends (i.e. social capital).

\section{References}

Attewell, P. (2001). The first and second digital divides. Sociology of Education, 74, 252-259.

Attewell, P. \& Battle, J. (1999). Home computers and school performance. Information Society, 15, 1-10.

Bose, K. (2017). Developmentally Appropriate Technology in Early Childhood (DATEC) in Botswana: In-Service Teachers' Perspectives. International Electronic Journal Of Elementary Education, 1(3), 218-231.

Bourdieu, P. (1990). In other words: Essays toward a reflective sociology. Stanford University Press.

Buckingham, D. (2004). New media, new childhoods? Children's changing cultural environment in the age of digital technology" in MJ Kehily. An Introduction to Childhood Studies, 124-139.

Bourdieu, P. (1997). The forms of capital in halsey, A., lauder, H., brown, P. \& stuart-wells, A. (Eds.) Education: Culture, Economy, Society. Oxford, Oxford University Press.

Bourdieu, P. (1986). Distinction: A social critique of the judgement of taste. London, Routledge.

Coffey, G. (2017). Literacy and technology: Integrating technology with small group, peer-led discussions of literature. International Electronic Journal of Elementary Education, 4(2), 395-405.

Coleman, J. S. (1988). Social capital in the creation of human capital. American Journal of Sociology, 94, 95120.

Corea, S. (2000). Cultivating technological innovation for development. Electronic Journal on Information Systems in Developing Countries, 2, 1-15.

Cuban, L. (2001). Oversold and underused: Computers in the classroom. Cambridge, Harvard University Press.

Cunningham M., Kerr, K., Mceune, R., Smith, P. \& Harris, S. (2003). Laptop for teachers; An evaluation of the first year of the initiative. Coventry, British Educational Communications and Technology Agency. 
Davies, C., Carter, A., Cranmer, S., Eynon, R. E., Furlong, J., Good, J., ... \& Holmes, W. (2008). The learner and their context-Interim report: Benefits of ICT use outside formal education.

DiMaggio, P., \& Hargittai, E. (2001). From the digital divide to digital inequality. In Presentation at the annual meetings of the American Sociological Association in Chicago.

Dutton, W., \& Helsper, E. (2007). The internet in Britain, Oxford, Oxford Internet Institute, University of Oxford.

Ersoy, A., \& Bozkurt, M. (2017). Understanding an elementary school teachers' journey of using technology in the classroom from sand table to interactive whiteboard. International Electronic Journal Of Elementary Education, 8(1), 1-20.

Facer, K., Furlong, J., Sutherland, R., \& Furlong, R. (2000). Home is where the hardware is: young people, the domestic environment and "access" to new technologies in Hutchby I and Moran-Ellis J (eds) Children, Technology and Culture.

Ginkel, S. van, Gulikers, J., Biemans, H.J.A., Noroozi, O., Roozen, M., Bos, T., Tilborg, R. van, Halteren, M. van, \& Mulder, M. (2019). Fostering oral presentation competence through a virtual reality-based task for delivering feedback. Computers \& Education (in press). https://doi.org/10.1016/j. compedu.2019.02.006.

Grenfell, M., \& James, D. (1998). Bourdieu and educationacts of practical theory (London, Falmer).

Harrison, C., Comber, C., Fisher, T., Haw, K., Lewin, C., Lunzer, E., ... \& Watling, R. (2002). ImpaCT2: The impact of information and communication technologies on pupil learning and attainment. British Educational Communications and Technology Agency.

Hayward, B., Alty, C., Pearson, S., \& Martin, C. (2002). Young people and ICT 2002: Findings from a survey conducted in autumn 2002.

Hesketh, A. J., \& Selwyn, N. (1999). Surfing to school: The electronic reconstruction of institutional identities. Oxford Review of Education, 25(4), 501-520.

Holloway, S. L., \& Valentine, G. (2003). Cyberkids: Children in the information age. Psychology Press.

Huda, M., Jasmi, K., Hehsan, A., Mustari, M., Shahrill, M., Basiron, B., \& Gassama, S. (2017). Empowering children with adaptive technology skills: Careful engagement in the digital Information age. International Electronic Journal of Elementary Education, 9(3), 693-708.

Jurich, S. (2000). The information revolution and the digital divide: a review of literature. TeckKnowLogia, 2, 42-44.

Lareau, A. (2001). Linking Bourdieu's concept of capital to the broader field. Social class, poverty, and education, 77-100.

Lazarus, W., \& Mora, F. (2000). Online Content for Low-Income and Underserved Americans: The Digital Divide's New Frontier. A Strategic Audit of Activities and Opportunities.
Lee, J. S., \& Bowen, N. K. (2006). Parent involvement, cultural capital, and the achievement gap among elementary school children. American educational research journal, 43(2), 193-218.

Livingstone, S., \& Haddon, L. (2009). EU kids online: Final report. London: London School of Economics and Political Science; EU Kids Online.

Morgan, J. N., \& Vanlengen, C. A. (2005). The digital divide and K-12 student computer use. Issues in Informing Science \& Information Technology, 2, 705-722.

Murdock, G., hartmann, P. \& gray, P. (1996). Conceptualising home computing: resources and practices. inneap, N., thomas, R., einon, G., mason, R. \& mackery, H. (Eds.) Information Technology and Society. London, Sage.

Noroozi, O. (2017). Considering students' epistemic beliefs to facilitate their argumentative discourse and attitudinal change with a digital dialogue game. Innovations in Education and Teaching International. http://dx.doi.org/10.1080/14703297.2016.120811 2.

Noroozi, O., Alikhani, I., Jarvela, S., Kirschner, P.A., Juuso, I., \& Seppänen, T. (2019a). Multimodal data to design visual learning analytics for understanding regulation of learning. Computers in Human Behavior. https://doi.org/10.1016/j.chb.2018.12.019.

Noroozi, O., Biemans, H.J.A., \& Mulder, M. (2016). Relations between scripted online peer feedback processes and quality of written argumentative essay. Internet and Higher Education, 31, 20-31.

Noroozi, O., Biemans, H.J.A., Busstra, M.C., Mulder, M., \& Chizari, M. (2011). Differences in learning processes between successful and less successful students in computer-supported collaborative learning in the field of human nutrition and health. Computers in Human Behaviour, 27(1), 309-318.

Noroozi, O., Biemans, H.J.A., Weinberger, A., Mulder, M., \& Chizari, M. (2013a). Scripting for construction of a transactive memory system in multidisciplinary CSCL environments. Learning and Instruction, 25(1), 1-12.

Noroozi, O., \& Hatami, J. (2018). The effects of online peer feedback and epistemic beliefs on students' argumentation-based learning. Innovations in Education and Teaching International (in press). https://doi.or g/10.1080/14703297.2018.1431143.

Noroozi, O., Hatami, J., Biemans, H.J.A., van Ginkel, S., \& Bayat, A. (2019b). Students' online argumentative peer feedback, essay writing, and content learning: Does gender matter?. Interactive Learning Environments. https://doi.org/10.1080/10494820.201 8.1543200 .

Noroozi, O., Kirschner, P., Biemans, H.J.A., \& Mulder, M. (2018). Promoting argumentation competence: Extending from first- to second-order scaffolding through adaptive fading. Educational Psychology Review, 30, 153-176.

Noroozi, O., \& Mulder, M. (2017). Design and evaluation of a digital module with guided peer feedback for student learning biotechnology and molecular life sciences, attitudinal change, and satisfaction. Biochemistry and Molecular Biology Education, 45(1), 
31-39.

Noroozi, O., Weinberger, A., Biemans, H.J.A., Mulder, M., \& Chizari, M. (2012). Argumentation-based computer supported collaborative learning (ABCSCL). A systematic review and synthesis of fifteen years of research. Educational Research Review, 7, 79-106.

Noroozi, O., Teasley, S.D., Biemans, H.J.A., Weinberger, A., \& Mulder, M. (2013b). Facilitating learning in multidisciplinary groups with transactive CSCL scripts. International Journal of Computer-Supported Collaborative Learning, 8(2), 189-223.

Noroozi, O., Weinberger, A., Biemans, H.J.A., Mulder, M., \& Chizari, M. (2013c). Facilitating argumentative knowledge construction through a transactive discussion script in CSCL. Computers and Education, $61,59-76$

Norris, P. (2001). Digital divide: Civic engagement, information poverty, and the Internet worldwide. Cambridge University Press.

Talaee, E. (2019). Longitudinal Impacts of Home Computer Use in Early Years on Children's Social and Behavioral Development. International Electronic Journa of Elementary Education, 11(3), 233-245. Retrieved from https://www.iejee.com/index.php/IEJEE/article/view/758

Talaee, E., Sylva, K., Evangelou, M., \& Noroozi, O. (2019). Longitudinal Impacts of Home Computer Use on Primary School Children's Reading and Mathematics Achievement. International Electronic Journal of Elementary Education, 11(2), 125-134. Retrieved from https://www.iejee.com/index.php/IEJEE/article/view/651

Telec, L., \& Tio, A. (1999). Falling through the Net: Defining the digital divide.

O'Dwyer, L. M., Russell, M., Bebell, D., \& Tucker-Seeley, K. R. (2005). Examining the Relationship between Home and School Computer Use and Students English/Language Arts Test Scores. Journal of Technology, Learning, and assessment, 3(3), n3.

Palfrey, J. G., \& Gasser, U. (2011). Born digital: Understanding the first generation of digital natives. Read How You Want. com.

Plowman, L., McPake, J., \& Stephen, C. (2008). Just picking it up? Young children learning with technology at home. Cambridge Journal of Education, 38(3), 303319.

Postman, N. (2011). Technopoly: The surrender of culture to technology. Vintage.

Rice, R. E. (2002). Primary issues in Internet use: Access, civic and community involvement, and social interaction and expression. Handbook of new media: Social shaping and consequences of ICTs, 105-129.

Scrimshaw, P. (2004). Enabling teachers to make successful use of ICT.

Selwyn, N. \& Facer, K. (2007). Beyond the digital divide, rethinking digital inclusion for the 21 st century, Futurelab.

Selwyn, N. (2003a). Defining the 'digital divide': Defining a theoretical understanding of inequalities in the information age. Cardiff University.
Selwyn, N. (2003b). Apart from technology: Understanding people's non-use of information and communication technologies in everyday life. Technology in Society, 25, 99-116.

Selwyn, N., Marriott, N., \& Marriott, P. (2000). Net gains or net pains? Business students' use of the Internet. Higher Education Quarterly, 54(2), 166-186.

Selwyn, N., Gorard, S., \& Furlong, J. (2006). Adult learning in the digital age: Information technology and the learning society. Routledge.

Selwyn, N. (2004). Reconsidering political and popular understanding of the digital divide. New Media and Society, 6, 341-362.

Somekh, B., mavers, D. \& lewin, C. (2003). Using ICT to enhance home-school links. Coventry, BECTA.

Stewart, A. (2000). Social inclusion: An introduction. Social Inclusion: Possibilities and Tensions. London: Macmillan, 1-16.

Valentine, G., Marsh, J., \& Pattie, C. (2005). Children and Young People's Home Use of ICT for Educational Purposes: The Impact on Attainment Ay Key Stages $1-4$.

Valero Haro, A., Noroozi, O., Biemans, H.J.A., \& Mulder, M. (2018). The effects of an online learning environment with worked examples and peer feedback on students' argumentative essay writing and domain-specific knowledge acquisition in the field of biotechnology. Journal of Biological Education. https://doi.org/10.1080/00219266.2018.1472132.

Valero Haro, A., Noroozi, O., Biemans, H., \& Mulder, M. (2019). First-and second-order scaffolding of argumentation competence and domain-specific knowledge acquisition: a systematic review. Technology, Pedagogy and Education, (in press). https:// doi.org/10.1080/1475939X.2019.1612772. (IF: 1.58, Q2; Ranking: 95/238 Education and Educational Research).

Vandijk, J. (1999). The network society: Social Aspects of New Media. London, Sage Publications.

Van Dijk, J., \& Hacker, K. (2003). The digital divide as a complex and dynamic phenomenon. The information society, 19(4), 315-326.

Vandijk, J. (2006) Digital divide research, achievements and shortcomings. Poetics, 34, 221-235.

Verstege, S., Pijeira-Díaz J.H., Noroozi, O., Biemans, H.J.A., \& Diederen, J. (2019). Relations between students' perceived levels of self-regulation and their corresponding learning behavior and outcomes in a virtual experiment environment. Computers in Human Behavior. https://doi.org/10.1016/j. chb.2019.02.020

Warschauer, M. (2004). Technology and social inclusion: Rethinking the digital divide. MIT press.

Yu, L. (2006). Understanding information inequality: Making sense of the literature of the information and digital divides. Journal of Librarianship and Information Science, 38(4), 229-252. 